\title{
Relação entre concentração e rentabilidade no setor bancário brasileiro
}

\section{A study on the relationship between concentration and profitability in the brazilian banking industry}

\author{
José Alves Dantas \\ Professor do Centro Universitário Unieuro e Doutorando do Programa Multiinstitucional e Inter-Regional de Pós-Graduação em Ciências \\ Contábeis - UnB/UFRN/UFPB. \\ E-mail: alves.dantas@bcb.gov.br \\ Otávio Ribeiro de Medeiros \\ Professor Titular do Departamento de Ciências Contábeis e Atuariais da Universidade de Brasília (UnB). \\ E-mail: otavio@unb.br \\ Edilson Paulo \\ Professor Adjunto II do Departamento de Finanças e Contabilidade (DFC) da Universidade Federal da Paraíba (UFPB). \\ E-mail: e.paulo@uol.com.br
}

Recebido em 03.08.2010 - Aceito em 22.10.2010 - 3a . versão aceita em 15.02.2011

\section{RESUMO}

O estudo da rentabilidade bancária envolve duas linhas de discussão: (1) a performance dos bancos é importante para garantir a solidez da instituição e a estabilidade do sistema e (2) rentabilidade elevada pode indicar comportamento oportunista dos bancos, associado a um mercado concentrado. O propósito deste estudo é avaliar a evolução do grau de concentração da indústria bancária no Brasil e verificar se há relação entre o nível de rentabilidade das instituições e o grau de concentração do setor, utilizando ativos totais, operações de crédito e depósitos bancários, entre janeiro/2000 e dezembro/2009. Tendo como benchmark os parâmetros das autoridades antitruste brasileiras, não foram encontradas evidências de concentração no setor, embora o indicador de concentração tenha aumentado substancialmente a partir do final de 2008. Utilizando os parâmetros considerados nos EUA, foi constatado que, no final do período analisado, os indicadores mostram uma situação de "concentração moderada". Como um segundo objetivo do trabalho, foram testadas hipóteses baseadas no paradigma estrutura - conduta - performance, que pressupõe que menor competição decorrente de maior concentração resultaria em maior rentabilidade das instituições. Os resultados não corroboram as hipóteses em nenhuma das combinações de testes realizadas, seja porque os parâmetros são não significativos ou porque são negativos. Não são confirmadas, portanto, as previsões de que a maior concentração do mercado explicaria uma maior rentabilidade das instituições financeiras, conforme a hipótese estrutura - conduta - performance (HCP). Ao contrário, foram obtidas evidências de que a hipótese de estrutura eficiente (HEE) explica, mais adequadamente, a rentabilidade no setor bancário nacional.

Palavras-chave: Bancos. Rentabilidade. Concentração. Competição. Instituições Financeiras.

\section{ABSTRACT}

The study of bank profitability involves two lines of discussion: (1) bank performance is important to guarantee the strength of the institution and the stability of the banking industry; and (2) a greater profitability might 
indicate that banks have an opportunistic behavior, associated to a concentrated market. This study is aimed at evaluating the degree of concentration of the Brazilian banking industry and verifying whether there is a relationship between the level of bank profitability and the sector's degree of concentration, based on total assets, credit operations and bank deposits from January 2000 to December 2009. Taking the parameters of Brazilian antitrust authorities as benchmarks, we cannot find evidence of concentration in the Brazilian banking industry, although it should be mentioned that the concentration indicator has increased substantially from the end of 2008 onwards. When we take the concentration parameters used in the US, we find that, by the end of the period, the indicators fall within the "moderate concentration" range. As a second aim of the paper, we test hypotheses based on the structure - performance paradigm, which assumes that less competition associated to higher concentration results in higher bank profitability. The results do not corroborate the hypotheses in any of the combined tests performed, because the parameters are either statistically insignificant or negative. Expectations that higher market concentration would explain higher bank profitability, according to the structure - performance hypothesis, are not confirmed. On the contrary, we find evidence that the efficient structure hypothesis explains the profitability of the Brazilian banking industry more adequately.

Keywords: Banks. Profitability. Concentration. Competition. Financial Institutions.

\section{INTRODUÇÃO}

O estudo sobre a rentabilidade das instituições bancárias tem como primeiro entendimento o fato de que esse é um aspecto importante para assegurar a sustentabilidade de cada banco e evitar consequências negativas para os depositantes e para o sistema financeiro como um todo, conforme destaca Couto (2002). Os casos das quebras bancárias na crise financeira de 2008, notadamente nos Estados Unidos e na Europa, suportam essa preocupação. Em contraponto, há, particularmente no Brasil, questionamentos quanto ao eventual "exagero" no nível de rentabilidade dessas instituições, que resultaria em distorções econômicas para o setor produtivo, sob o argumento de que esse retorno "excessivo" seria alcançado por meio de cobranças de altas taxas de juros e tarifas bancárias desproporcionais. Os representantes das instituições financeiras reagem comumente a esse entendimento argumentando que a razão para as altas taxas de juros seria decorrente da carga tributária, do risco de inadimplência e do custo administrativo de se manter um sistema financeiro integrado e automatizado e que as forças de mercado corrigiriam eventuais distorções.
$\mathrm{Na}$ opinião dos críticos, porém, o argumento de que as forças de mercado corrigiriam as imperfeições localizadas não se sustenta, tendo em vista que o Sistema Financeiro Nacional (SFN) apresentaria evidências de concentração, principalmente em decorrência dos atos de incorporações. Carvalho (2007), por exemplo, destaca que a preocupação com a concorrência no sistema financeiro brasileiro é antiga e que os juros persistentemente altos cobrados pelos bancos sempre alimentaram a suspeita de um "déficit de concorrência no setor".

Nesse contexto, este estudo tem por propósito avaliar a evolução do grau de concentração da indústria bancária, contribuindo para a discussão sobre o nível de competição (ou ausência de) no sistema financeiro nacional, bem como verificar se há relação entre o nível de rentabilidade das instituições e o grau de concentração do setor, utilizando os parâmetros de ativos totais, operações de crédito e depósitos bancários.

Pretende-se, assim, obter elementos empíricos para dar substância às discussões sobre o funcionamento do SFN, não só com dados objetivos sobre o grau de competição do setor, mas também avaliando os efeitos 
de uma variação no grau de concentração da indústria no nível de rentabilidade das instituições. Uma relação positiva entre as medidas de concentração e de rentabilidade pode sugerir que os bancos atuam oportunisticamente, aproveitando o seu poder de mercado para impor preços e condições aos clientes, aumentando a sua performance.

Para esses objetivos, são realizados testes empíricos com dados dos balancetes mensais de janeiro/2000 a dezembro/2009 das instituições bancárias - exceto bancos de desenvolvimento e cooperativas de crédito - com carteiras de depósitos e de crédito ativas.

\section{REFERENCIAL TEÓRICO}

\subsection{Efeitos positivos e negativos da concentração bancária}

A competição, no mercado bancário, é geralmente um aspecto desejável porque conduz ao aumento da eficiência institucional, a menores custos para os clientes e à melhoria na qualidade e abrangência dos serviços financeiros oferecidos (WB; IMF, 2005). Segundo Freitas e Köhler (2009), a maior concentração implica maior oportunidade de abuso de poder econômico e consequente aumento dos spreads, mas, por outro lado, se houver ganhos significativos de escala, o custo pode cair.

Essa dualidade, também, é destacada por Gelos (2006), ao afirmar que, em um ambiente de competição imperfeita se pode ter comportamentos distintos: grandes bancos podem explorar a economia de escala e cobrar margens menores; instituições com maior participação podem aproveitar a oportunidade e cobrar taxas mais elevadas e bancos com maiores custos podem repassá-los para os tomadores de crédito. Na mesma linha de entendimento, Beck, Demirgüç-Kunt e Levine (1999) destacam que um mercado bancário muito concentrado pode resultar em perda de pressão competitiva para atrair investimentos e alocar eficientemente os recursos disponíveis, mas, por outro lado, um mercado fortemente fragmentado pode apontar para uma descapitalização dos bancos. Argumentação equivalente é destacada por Araújo e Jorge Neto (2007), ao constatarem que um maior grau de competição no setor leva a uma maior exposição a riscos.

Esse conflito entre os riscos e benefícios da concentração bancária é exemplificado na afirmação de Pagotto (2006) sobre a atuação do agente regulador no processo de autorização para funcionamento das instituições. Para ele, um regime de autorização mais estrito eleva barreiras à entrada, diminuindo a concorrência, mas se são estabelecidos critérios mais frouxos, pode ocorrer o aumento da concorrência à custa da higidez do sistema.

Em função do debate sobre a consolidação bancária e as previsões teóricas conflitantes sobre o relacionamento entre a estrutura de mercado do setor financeiro e a fragilidade das instituições, Beck, Demirgüç-Kunt e Levine (2003) avaliaram o impacto da concentração bancária, da regulação do setor e das instituições nacionais na probabilidade de ocorrer uma crise sistêmica. Usando dados de setenta países, de 1980 a 1997, os autores concluíram que crises dessa natureza são menos prováveis em sistemas bancários mais concentrados, com menores restrições regulatórias sobre competição e atividade bancária e com a existência de instituições que encorajem a competição. Particularmente em relação à concentração, o pressuposto é de que ela aumenta a probabilidade de lucros, reduzindo a fragilidade bancária, porque maiores lucros criam um colchão contra choques adversos e aumenta o valor intrínseco do banco, reduzindo os incentivos para que esses assumam riscos excessivos. 
Em síntese, é possível concluir que, embora a competição seja geralmente desejável, pelos efeitos benéficos que gera, principalmente em relação à eficiência do setor, à qualidade dos serviços prestados e aos preços cobrados, a concentração, também, tem aspectos positivos para o setor, em particular a sua contribuição para a higidez e a estabilidade do sistema.

\subsection{Parâmetros para se avaliar a competitividade ou concentração de mercado}

Discutidos os seus efeitos positivos e negativos, a questão é como se mensurar o nível de competitividade ou concentração do mercado. De acordo com Carvalho (2007), os estudos sobre concentração bancária não têm como enfrentar a questão central de que concentração é apenas uma proxy, e não especialmente expressiva, para a variável que se quer explicar: o padrão de competição. Considerada essa ressalva inicial, são apontadas, na literatura, várias medidas de competição do setor financeiro, incluindo: o número total de instituições financeiras; as mudanças na participação no mercado; a facilidade para ingresso no mercado; o spread bancário e o preço dos serviços financeiros; entre outras (WB; IMF, 2005).

Medidas de concentração baseadas na participação no mercado dos maiores bancos ou no Índice Herfidahl-Hirschman (HHI), que usa a participação no mercado de cada banco para obter uma medida síntese simples da concentração do setor, geralmente são usadas como indicadores de competição, mas decidir o que é concentrado e o que não é depende de uma grande parcela de julgamento, tornando-se crítico o estabelecimento de um benchmark (WB; IMF, 2005). Polder et al. (2009), também, destacam o HHI e as participações das três (C3), das quatro (C4) ou das cinco (C5) maiores organizações como parâmetros mais utilizados para se apurar o nível de concentração do setor. Não obstante a recorrência na utilização desses indicadores, Nakane (2003) ressalta que podem ser medidas imperfeitas de poder de mercado.

Comparando os tipos de indicadores, Masciandaro e Quintyn (2009) ressaltam que o HHI tem prevalecido em relação aos outros por ter maior influência junto às autoridades. Particularmente nos Estados Unidos da América (EUA), os Horizontal Merger Guidelines, instituídos pelo U.S. Department of Justice e pela Federal Trade Commission, utilizam o HHI como referência para a análise das ações antitruste, sob o argumento de que ele considera a participação de todas as instituições que compõem o mercado e não apenas a das maiores instituições, tendo por base os intervalos destacados no Quadro 1.

Quadro 1 Definição do grau de concentração, conforme Horizontal Merger Guidelines

\begin{tabular}{|l|l|}
\hline HHI & Grau de competição/concentração \\
\hline Abaixo de 0,10 & Indica mercado não concentrado. \\
\hline Entre 0,10 e 0,18 & Indica mercado com concentração moderada. \\
\hline Acima de 0,18 & Indica mercado altamente concentrado. \\
\hline
\end{tabular}

Fonte: U.S. Department of Justice e Federal Trade Commission

No Brasil, a referência para a avaliação das ações antitruste é o Guia de Análises para Atos de Concentração Horizontal, instituído por meio da Portaria Conjunta no 50, de 1.8.2001, da Secre- taria de Acompanhamento Econômico (SEAE) e da Secretaria de Direito Econômico (SDE). De acordo com a norma, considera-se que a concentração viabiliza o exercício coordenado de poder 
de mercado quando as quatro maiores empresas (C4) possuírem participação igual ou superior a $75 \%$ do mercado. Cabe ressaltar, conforme Diana (2010), que, no caso do sistema financeiro, há discussões judiciais sobre a competência para julgar atos de concentração: se é atribuição das autoridades antitruste ou do BCB.

Ainda sobre a adequação dos níveis de concentração para medir a competitividade, Claessens e Laeven (2004) avaliaram dados de instituições de 50 países, medindo o nível de competição como a extensão com que mudanças nos preços dos inputs se refletem nas receitas dos bancos, não encontrando relação relevante entre essa medida e o grau de concentração. De acordo com Beck, Demirgüç-Kunt e Levine (2009), não obstante essa evidência, a concentração continua a ser amplamente utilizada como indicador de competição de um sistema bancário, princi- palmente pela ausência de dados detalhados de cada instituição.

\subsection{Estudos sobre o grau de concentração na indústria bancária brasileira}

Segundo Faria, Paula e Marinho (2007), o SFN passou por mudanças profundas nos últimos anos, principalmente em função do processo de reestruturação decorrente da ameaça de crise durante os anos 1990, o que provocou uma onda de fusões e aquisições, além da entrada de instituições estrangeiras no mercado varejista, com um importante movimento de consolidação. As estatísticas sobre os casos de cisões, fusões e incorporações verificados entre 1998 e 2009 (Tabela 1) confirmam a recorrência desse tipo de evento, com uma maior concentração no último exercício.

Tabela 1 Número de ocorrências de cisões, fusões e incorporações bancárias no SFN entre 1998 e 2009

\begin{tabular}{l|l|l|l|l|l|l|l|l|l|l|l|l}
\hline Ano & $\mathbf{1 9 9 8}$ & $\mathbf{1 9 9 9}$ & $\mathbf{2 0 0 0}$ & $\mathbf{2 0 0 1}$ & $\mathbf{2 0 0 2}$ & $\mathbf{2 0 0 3}$ & $\mathbf{2 0 0 4}$ & $\mathbf{2 0 0 5}$ & $\mathbf{2 0 0 6}$ & $\mathbf{2 0 0 7}$ & $\mathbf{2 0 0 8}$ & $\mathbf{2 0 0 9}$ \\
\hline $\begin{array}{l}\text { No cisões, fusões e } \\
\text { incorporações }\end{array}$ & 3 & 1 & 3 & 1 & 2 & 4 & 2 & 2 & 3 & 2 & 1 & 11 \\
\hline
\end{tabular}

Fonte: Elaborado pelos autores, a partir de dados disponíveis na página do BCB na internet.

Com a premissa de que uma primeira evidência de maior concentração do mercado pode ser a evolução do número de instituições, analisou-se o número de bancos (considerados os bancos múltiplos, os bancos comerciais e as caixas econômicas) no SFN entre 1994 e 2009 (Tabela 2), constatando-se que a quantidade de instituições financeiras passou de 246 para 158, o que equivale a uma redução de $36 \%$.

Tabela 2 Evolução do número de bancos no Sistema Financeiro Nacional, de 1994 a 2009

\begin{tabular}{c|c|c|c|c|c|c|cc}
\hline Ano & Bancos & Ano & Bancos & Ano & Bancos & Ano & Bancos \\
\hline 1994 & 246 & 1998 & 204 & 2002 & 167 & 2006 & 159 \\
\hline 1995 & 242 & 1999 & 195 & 2003 & 165 & 2007 & 156 \\
\hline 1996 & 234 & 2000 & 192 & 2004 & 164 & 2008 & 159 \\
\hline 1997 & 218 & 2001 & 182 & 2005 & 161 & 2009 & 158 \\
\hline
\end{tabular}

Fonte: Elaborado pelos autores, a partir de dados disponíveis na página do BCB na internet. 
Esses dados reforçam as suspeitas de que o grau de concentração do mercado bancário teria aumentado nesse período. Sob outra ótica, a existência de mais de 150 bancos pode sugerir que não existem evidências de que o mercado não seja competitivo. De qualquer forma, esse não é um parâmetro reconhecido na literatura como apropriado para se concluir sobre o nível de competitividade, oferecendo apenas indícios de que a redução do número de participantes pode se refletir na redução da competitividade do setor.

Muito embora a discussão sobre o grau de concentração do SFN seja recorrente, estudos que procurem avaliar especificamen- te o nível de competição não são comuns ${ }^{1}$. Uma referência em pesquisas dessa natureza é o estudo de Beck, Demirgüç-Kunt e Levine (1999), que sob o patrocínio do Banco Mundial, promoveram uma comparação do nível de concentração dos sistemas financeiros de diversos países, usando como parâmetro de mensuração a participação no mercado dos três maiores bancos (C3), tendo por base os ativos totais. Esses dados são periodicamente atualizados na página do Banco Mundial na internet, sendo a última revisão promovida em abril/2010, com os dados do ano de 2008. Os resultados em relação ao Brasil são sintetizados na Tabela 3.

Tabela 3 Evolução da concentração bancária no Brasil no ranking do Banco Mundial - 1994 a 2008

\begin{tabular}{c|c|c|c|c|c}
\hline Ano & Indicador & Brasil no Ranking & Ano & Indicador & Brasil no Ranking \\
\hline 1994 & 0,4598 & $20^{\circ}$ lugar em 107 países & 2002 & 0,4184 & $15^{\circ}$ lugar em 144 países \\
\hline 1995 & 0,4148 & $13^{\circ}$ lugar em 116 países & 2003 & 0,4818 & $22^{\circ}$ lugar em 148 países \\
\hline 1996 & 0,3670 & $11^{\circ}$ lugar em 126 países & 2004 & 0,4632 & $21^{\circ}$ lugar em 153 países \\
\hline 1997 & 0,3923 & $12^{\circ}$ lugar em 134 países & 2005 & 0,4431 & $19^{\circ}$ lugar em 155 países \\
\hline 1998 & 0,3874 & $14^{\circ}$ lugar em 133 países & 2006 & 0,5404 & $39^{\circ}$ lugar em 153 países \\
\hline 1999 & 0,3862 & $12^{\circ}$ lugar em 135 países & 2007 & 0,6639 & $56^{\circ}$ lugar em 136 países \\
\hline 2000 & 0,3815 & $12^{\circ}$ lugar em 146 países & 2008 & 0,8324 & $82^{\circ}$ lugar em 135 países \\
\hline 2001 & 0,3847 & $9^{\circ}$ lugar em 141 países & & & \\
\hline
\end{tabular}

Fonte: Elaborado pelos autores, a partir de dados do Banco Mundial.

Nota: O ranking parte dos países menos concentrados para os mais concentrados

Como se percebe, em 1994, o Brasil ocupava a $20^{\text {a }}$ posição no ranking dos setores bancários menos concentrados, quando os três maiores bancos respondiam por cerca de $46 \%$ dos ativos do sistema. Em 2001, o país chegou a ocupar a $9^{a}$ posição, mas, nos últimos anos, constata-se um aumento do indicador, passando os três maiores bancos a responderem, em 2008, por mais de $83 \%$ dos ativos do sistema. Com isso, o Brasil passou a ocupar a $82^{\text {a }}$ posição no ranking dos menos concentrados, em um conjunto de 135 países pesquisados.
Entre os trabalhos que focam, especificamente, o mercado brasileiro, as conclusões são, de certa forma, contraditórias. Nakane (2003), por exemplo, utilizou o HHI, considerando as variáveis "Ativos", "Créditos" e "Depósitos", entre 1994 e 2003, concluindo que, de forma geral, os índices não indicam concentração, com exceção de quatro anos do período examinado, em que o mercado de crédito apresentou índice considerado como de concentração moderada. Ressalta, adicionalmente, que os estudos examinados demonstram que os bancos brasileiros ope-

Na prática, grande parte das pesquisas que tratam da concentração avalia a sua associação com o nível de spread, como destacado na seção 2.5 
ram em estruturas de mercado imperfeitas, mas apresentando elevado grau de concorrência. Conclusão equivalente é apresentada por Belaisch (2003), cujo estudo mostrou que a hipótese de que os bancos brasileiros atuam monopolisticamente é rejeitada, embora seja também rejeitada a hipótese de competição perfeita no sistema. Essa é a mesma evidência apresentada por Araújo e Jorge Neto (2007), ao constatarem que a estrutura que caracteriza o grau de competição no mercado bancário brasileiro é a concorrência monopolista, tendo em vista que as hipóteses de concorrência perfeita e de monopólio são rejeitadas.

Pagotto (2006), por sua vez, destaca que, embora não se possa afirmar que o setor financeiro opere sob concorrência perfeita, estudos empíricos descartam a hipótese de monopólio e presença de cartéis, sendo difícil emitir um juízo de valor sobre o nível de concorrência no SFN. A presença de um grande número de empresas, segundo o autor, afasta o sistema do conceito clássico de oligopólio, mas contra esse raciocínio pode-se alegar que apenas um seleto grupo de grandes instituições é importante, as quais atuariam como líderes.

No outro extremo, Carvalho (2007) é categórico ao afirmar ser incontroverso que a estrutura do mercado bancário brasileiro está longe de ser competitiva, com a prevalência dos dois maiores bancos privados em qualquer segmento do mercado que se considere.

Em síntese, a revisão dos estudos realizados sobre o grau de concentração na indústria bancária brasileira apresenta conclusões relativamente distintas quanto ao nível de competitividade do setor, o que aumenta a importância de se procurar atualizar os exames empíricos a respeito.

\subsection{Pressupostos teóricos da relação entre concentração e rentabilidade}

Na literatura, ao se mencionar a questão da concentração no sistema financeiro, geralmente se procura avaliar o seu impacto no spread bancário, que, por sua vez, conforme Carvalho (2007), é associado à lucratividade. Souza (2007) ressalta, porém, que o lucro é apenas um dos componentes do spread e não exatamente a mesma coisa. Freitas e Köhler (2009) reforçam esse entendimento, destacando que o spread é composto de cinco componentes: custo administrativo; prêmio pelo risco de inadimplência; custo do compulsório; tributos e taxas e resíduo.

A relação entre o spread e a lucratividade dá-se por meio desse último componente, o resíduo, que corresponde à diferença entre o spread total e a soma dos quatro componentes anteriores. Segundo Freitas e Köhler (2009), a interpretação do resíduo permite afirmar que representa a soma de três fatores: o lucro competitivo, correspondente à remuneração dos bancos caso atuassem em sistema de concorrência perfeita; a renda econômica, decorrente do poder de mercado da instituição e um prêmio pelo risco incorrido, tanto pelo descasamento de prazos entre ativos e passivos, quanto pela probabilidade de não recebimento dos créditos.

Deduz-se, assim, que o efeito da concentração do sistema no spread se dá no componente resíduo, em particular no fator relativo à "renda decorrente do poder de mercado da instituição". Assim, ao se discutir o impacto da concentração no spread, indiretamente se avaliam os efeitos do poder de mercado das instituições em suas taxas de rentabilidade. Em sentido inverso, as pesquisas que examinam a relação entre a rentabilidade das instituições e o grau de concentração do mercado, como o presente estudo, também contemplam, indiretamente, uma avaliação do impacto do poder de mercado no spread. Cabe ressaltar que a abrangência, nesse caso, é mais ampla, envolvendo, também, outras atividades e serviços bancários, além das operações de captação e empréstimos (base para a apuração do spread).

Não obstante a relação entre concentração e rentabilidade bancária ser, de certa forma, 
intuitiva, não há consenso quanto ao tipo de comportamento esperado. Segundo Berger e Hannan (1989, apud BROCK; FRANKEN, 2002), é possível encontrar, na literatura, duas hipóteses opostas relativas ao impacto da concentração no comportamento dos bancos em precificar os seus produtos e serviços. De um lado, a hipótese estrutura-conduta-performance (HCP) prevê que uma indústria bancária mais concentrada se comportará oligopolisticamente. De outro, a hipótese da estrutura eficiente (HEE) prevê que a concentração é decorrência da eliminação de instituições menos eficientes pelas contrapartes mais eficientes.

Essas premissas são reforçadas por Havrylchyk e Jurzyk (2006), ao afirmarem que uma das hipóteses mais testadas na literatura da rentabilidade é o paradigma HCP, que pressupõe que maior concentração do mercado causa menor competição e resulta em maior rentabilidade dos bancos, tendo como explicação alternativa para o relacionamento positivo entre concentração e rentabilidade, a hipótese HEE, definida por Demsetz (1973, apud HAVRYLCHYK; JURZYK, 2006) como o pressuposto de que bancos mais eficientes, que são mais rentáveis, ganham poder de mercado adicional, levando à concentração da indústria.

\subsection{Estudos sobre os efeitos da concentração no spread ou na rentabilidade bancária}

Como já destacado, grande parte das pesquisas que tratam dos efeitos da concentração bancária avaliam sua associação com o nível de spread (PERIA; MODY, 2002; BROCK; FRANKEN, 2002; NAKANE, 2003; GELOS, 2006; ALENCAR; LEITE; FERREIRA, 2007).

Peria e Mody (2002) examinaram os efeitos da concentração no spread bancário em cinco países da América Latina (Argentina, Chile, Colômbia, México e Peru), encontrando uma relação positiva entre essas medidas. Já Brock e Franken (2002), utilizando dados das instituições chilenas, avaliaram o impacto da concentração do sistema na margem líquida e no spread bancário, encontrando resultados mistos: uma relação positiva e estatisticamente significante com a margem líquida, suportando a hipótese HCP e uma relação negativa, também estatisticamente relevante, com o spread bancário, favorecendo a hipótese HEE. Esse estudo demonstra, portanto, que embora haja associação entre lucratividade e spread, os efeitos da concentração nessas duas medidas não são necessariamente equivalentes.

Examinando dados específicos do mercado brasileiro de 1994 a 2003, Nakane (2003) concluiu não existir muito fundamento na ideia de que os elevados spreads bancários observados no país sejam decorrência da baixa concorrência no setor, não obstante a forte participação da margem líquida dos bancos na composição do spread.

Resultados mistos foram encontrados por Gelos (2006), no estudo que procurou identificar os determinantes do spread bancário na América Latina. Entre as variáveis testadas, foi incluída a concentração do sistema, medida de duas formas, o C5 e o HHI. Os resultados demonstraram que a maior concentração, medida pelo C5, é associada com maiores margens líquidas de juros. Ao se utilizar o HHI, as estimações não se mostraram significantes.

Com o propósito de avaliar o comportamento da margem líquida de juros, o spread bancário, em dezessete países, entre os quais $\mathrm{o}$ Brasil, Alencar, Leite e Ferreira (2007) constataram, entre outros achados, que a sua relação com a concentração bancária, medida pela participação dos três maiores bancos, é negativa.

Além dos estudos que associam o grau de concentração ao spread, também há pesquisas que examinam, diretamente, o relacionamento entre as medidas de concentração e de performance. É o caso, por exemplo, de Havrylchyk e Jurzyk (2006), que encontraram uma associação positiva entre a rentabilidade, medida pelo retorno sobre os ativos, e o grau de concentração do sistema, medido pelo HHI. Esses resultados são consistentes com a hipótese de que a estrutura conduz a uma melhor performance (HCP). 


\section{METODOLOGIA}

Os testes empíricos realizados têm como objeto os dados contábeis constantes nos balancetes mensais de janeiro/2000 a dezembro/2009 das instituições bancárias, exceto bancos de desenvolvimento e cooperativas de crédito, com carteiras de depósitos (conta 41000007) e de crédito (conta 16000001) ativas. Atendem a esse requisito 201 instituições, sendo que cada uma delas não necessariamente possui dados para todo o período selecionado, tendo em vista que: algumas foram descontinuadas por processos de aquisição, fusão, incorporação, liquidação etc. e outras foram constituídas durante o período da amostra.

Tanto esses dados contábeis, quanto as outras informações necessárias aos testes empíricos, são obtidos na página do Banco Central do Brasil (BCB) na internet, nos links de "informações contábeis", de "séries temporais" e de "composição e evolução do SFN".

\subsection{Grau de concentração ou de competição}

A primeira etapa dos testes empíricos consiste na apuração e análise do grau de concentração da indústria bancária, tendo por base a participação dos quatro maiores bancos (C4) no mercado e o HHI, em relação aos parâmetros: ativos totais (contas 10000007 e 2000004); operações de crédito (conta 16000001) e depósitos bancários (conta 41000007).

A apuração do indicador $\mathrm{C} 4$, em cada período $(t)$, dá-se pelo somatório da participação $(p)$ dos quatro maiores bancos em cada parâmetro específico - ativos totais, créditos e depósitos -, de acordo com a fórmula (1).

$C 4_{t}=\sum_{i=1}^{4} p_{i}$

No caso do HHI, a apuração do indicador em cada período $(t)$ ocorre com o somatório do quadrado da participação $(p)$ de todas as instituições financeiras ( $i$ variando de 1 a $N$ ) em cada parâmetro específico, seguindo a fórmula (2).

$H I_{t}=\sum_{i=1}^{N} p_{i}^{2}$

Para se concluir sobre o nível de competição da indústria serão considerados: os critérios estabelecidos no Guia de Análises para Atos de Concentração Horizontal, publicados pela Portaria Conjunta SEAE/SDE no 50/2001, na avaliação do indicador $\mathrm{C} 4$ e os parâmetros definidos pelo Departamento de Justiça dos Estados Unidos, por meio dos Horizontal Merger Guidelines, na análise do HHI. A respeito desses parâmetros normativos para avaliação dos atos de concentração, cabe ressaltar que essa é a principal razão para se adotarem, no presente estudo, esses dois tipos de indicadores de concentração: C4 e HHI, ou seja, o propósito é utilizar benchmarks que sejam aceitos como referência pelas autoridades antitruste. Assim, serão testadas as seguintes hipóteses de pesquisa:

$H_{1} \quad O$ mercado bancário brasileiro apresenta evidências de concentração, de acordo com os parâmetros instituídos no Guia de Análises para Atos de Concentração Horizontal, divulgados pela Portaria Conjunta SEAE/ SDE $n^{\circ}$ 50/2001.

$\mathrm{H}_{2} \mathrm{O}$ mercado bancário brasileiro apresenta evidências de concentração, de acordo com os parâmetros instituídos no Horizontal Merger Guidelines, editados pelo Departamento de Justiça dos Estados Unidos.

\subsection{Relação entre rentabilidade e grau de concentração/ competição}

Na segunda etapa dos testes empíricos, considerando-se as premissas da hipótese estrutura - conduta - performance (HCP), que relaciona o nível de concentração econômica e a possibilidade de rentabilidade oportunista, são testadas as seguintes hipóteses de pesquisa: 
$\mathrm{H}_{3}$ A rentabilidade das instituições bancárias brasileiras é positivamente relacionada com o grau de concentração do sistema financeiro nacional.

$\mathrm{H}_{4} \quad \mathrm{~A}$ rentabilidade das instituições bancárias brasileiras é positivamente relacionada com a sua participação no mercado (variável tamanho).

Essas hipóteses são testadas em relação aos parâmetros de ativos totais, créditos e depósitos, utilizando-se como referência para os testes empíricos o modelo (3):

$R_{i, t}=\beta_{0}+\beta_{1} C_{t}+\beta_{2} P_{i, t}+\beta_{3} J_{t}+\beta_{4} E_{t}+\beta_{5} D_{t}+\varepsilon_{i, t}$

em que:

$R$ Retorno sobre os Ativos $^{2}$ da instituição $i$, no período $t$, apurado de acordo com a fórmula (4), considerando: as receitas operacionais $^{3}(R O)$ - conta 71000008; as despesas operacionais ${ }^{4}(D O)$ - conta 81000005; e os ativos totais $(A T)$ - contas 10000007 e 2000004.

$$
R_{i, t}=\frac{R O_{i, t}-D O_{i, t}}{\left(A T_{i, t}+A T_{i, t-1}\right)} / 2
$$

$C$ Índice de participação dos quatro maiores bancos (C4) ou Índice Herfildahl Hirschman (HHI),indicativos do grau de concentração no SFN, no momento $t$, apurados de acordo com os modelos (1) e (2), respectivamente, em relação aos parâmetros de ativos totais $(a t)$, de operações de crédito $(c r)$ ou de depósitos bancários $(d p)$.

$P$ Participação relativa da instituição $i$ no total dos ativos (at), dos depósitos bancários $(d p)$ e das operações de crédito $(c r)$ no sistema financeiro nacional, no período $t$.

$J$ Taxa real de juros da economia - taxa básica de juros (Selic) deflacionada pelo Índice de Preços ao Consumidor Ampliado (IPCA), para eliminar da relação as eventuais distorções provocadas pelos efeitos inflacionários.

$E$ Índice de atividade econômica, representado pela variação trimestral do Produto Interno Bruto (PIB) - dados dessazonalizados - valor adicionado a preços básicos - série 1251 do BCB.

$D$ Variação cambial, em percentual, apurada em função da taxa de câmbio livre - preço do dólar americano em reais série 3696 do BCB. Variações positivas traduzem a depreciação da moeda doméstica em relação ao dólar, enquanto variações negativas refletem movimento de apreciação do real.

Como se percebe, além das variáveis diretamente relacionadas às hipóteses de pesquisa ( $\mathrm{C} 4, \mathrm{H}$ e P), o modelo (3) incorpora variáveis representativas da taxa de juros da economia (J), do nível de atividade econômica (E) e da variação cambial do dólar americano (D), como forma de controlar os efeitos dessas medidas macroeconômicas no comportamento da variável dependente, aumentando a robustez dos achados. O pressuposto para o uso dessas variáveis é que a rentabilidade das instituições bancárias tem relação com as condições macroeconômicas conjunturais, sendo conveniente o seu controle para que os resultados da relação que se quer testar - rentabilidade e concentração - de forma a reduzir os eventuais efeitos de variáveis omitidas.

Embora os sinais encontrados nessas variáveis de controle não sejam essenciais

2 Havrylchyk eJurzyk (2006) destacam que a literatura oferece um grande número de definições de rentabilidade, com destaque particular para a medida contábil representativa do Retorno sobre os Ativos, justificando a escolha dessa medida em seu estudo sobre a relação entre a rentabilidade e a concentração bancária. Essa medida de performance também é utilizada por Choi e Kotrozo (2006) e por Beck, Demirgüç-Kunt e Levine (2009), em estudos sobre a indústria bancária.

3 Contemplam as rendas de operações de crédito, de câmbio, de aplicações interfinanceiras de liquidez, com títulos e valores mobiliários e instrumentos financeiros derivativos, de prestação de serviços, de participações e outras receitas.

4 Contemplam as despesas de captação, de obrigações por empréstimos e repasses, de câmbio, com títulos e valores mobiliários e instrumentos financeiros derivativos, de participações, administrativas, aprovisionamentos e ajustes patrimoniais e outras despesas. 
para os propósitos específicos do presente estudo, sendo incorporadas com o objetivo de capturar os seus efeitos, quaisquer que sejam eles, para dar robustez às conclusões em relação às variáveis de interesse, são esperadas relações positivas entre a rentabilidade das instituições e: (i) o nível da taxa de juros da economia, tendo em vista os seus efeitos nas taxas de juros praticadas nas operações de crédito e nas operações ativas indexadas; (ii) e o nível de atividade econômica, considerando o pressuposto de que nos momentos de crescimento econômico há um aumento na demanda por crédito e, consequentemente, maiores oportunidades de incremento no volume das carteiras de crédito e de majoração nas taxas de juros praticadas.

No caso específico da variação cambial, o impacto na rentabilidade das instituições depende da posição que o banco mantém no mercado de câmbio. Se estiver "comprado", uma variação positiva traz reflexos positivos para o resultado em reais, enquanto se tiver na posição "vendida", a variação positiva no câmbio impacta no resultado negativamente. Se ocorrer uma variação negativa na taxa de câmbio, o raciocínio é o inverso. Para os propósitos do presente estudo, espera-se uma relação positiva entre a variação cambial e a rentabilidade das instituições financeiras, partindo-se do pressuposto de que os bancos teriam a capacidade de se antecipar aos movimentos do câmbio, ajustando sua posição no mercado - "comprada" antes de uma variação positiva e "vendida" antes de uma variação negativa - potencializando os seus resultados, em reais.

\section{ANÁLISE DOS DADOS}

O processo de apuração e análise dos dados contempla duas etapas: a avaliação do grau de concentração/competição no SFN e o estudo da relação entre esse grau de concentração e a rentabilidade das instituições bancárias.

\subsection{Grau de concentração/ competição na indústria bancária brasileira}

Tendo por base os dados das instituições integrantes da amostra, foram apurados os índices de concentração C4 e HHI da indústria bancária brasileira, no período de janeiro/2000 a dezembro/2009, em relação aos parâmetros de ativos totais, operações de crédito e depósitos bancários, cujas estatísticas descritivas estão descritas na Tabela 4, juntamente com as demais séries utilizadas no estudo.

Tabela 4 Estatísticas descritivas das séries utilizadas no estudo

\begin{tabular}{l|c|c|c|c|c|c|c}
\hline Medida & $\mathbf{C 4}_{\mathbf{a t}}$ & $\mathbf{C 4}_{\mathbf{c r}}$ & $\mathbf{C 4}_{\mathbf{d p}}$ & $\mathbf{H H I}_{\mathbf{a t}}$ & $\mathbf{H H I}_{\mathbf{c r}}$ & $\mathbf{H H I}_{\mathbf{d p}}$ & $\mathbf{R}$ \\
\hline Média & 0,4786 & 0,4685 & 0,5486 & 0,0729 & 0,0797 & 0,0919 & 0,0016 \\
\hline Mediana & 0,4764 & 0,4607 & 0,5441 & 0,0719 & 0,0753 & 0,0898 & 0,0017 \\
\hline Desvio Padrão & 0,0344 & 0,0504 & 0,0210 & 0,0090 & 0,0163 & 0,0061 & 0,0169 \\
\hline Máximo & 0,5871 & 0,5948 & 0,6293 & 0,1040 & 0,1165 & 0,1152 & 0,1922 \\
\hline Mínimo & 0,4123 & 0,3854 & 0,5238 & 0,0573 & 0,0541 & 0,0849 & $-1,4456$ \\
\hline
\end{tabular}




\begin{tabular}{l|c|c|c|c|c|c|c|}
\hline continuação & \multicolumn{1}{c}{$\mathbf{P}_{\text {at }}$} & $\mathbf{P}_{\mathbf{c r}}$ & $\mathbf{P}_{\mathbf{d p}}$ & $\mathbf{J}$ & $\mathbf{E}$ & $\mathbf{D}$ & \\
\hline Medida & 0,0069 & 0,0069 & 0,0070 & 0,0897 & 0,0083 & 0,0018 & \\
\hline Média & 0,0008 & 0,0008 & 0,0005 & 0,0932 & 0,0108 & $-0,0062$ \\
\hline Desvio Padrão & 0,0215 & 0,0225 & 0,0244 & 0,0251 & 0,0112 & 0,0557 \\
\hline Máximo & 0,1855 & 0,2933 & 0,2118 & 0,2421 & 0,0274 & 0,2887 \\
\hline Mínimo & 0,0000 & 0,0000 & 0,0000 & 0,0420 & $-0,0314$ & $-0,1382$ & \\
\hline
\end{tabular}

Em que: $\mathrm{C} 4$ = índice de participação dos quatro maiores bancos; $\mathrm{HHI}=$ índice Herfildahl-Hirschman; $\mathrm{P}=$ participação de cada banco no mercado; $\mathrm{I}=$ taxa de juros real da economia; $\mathrm{E}$ = indicador de atividade; $\mathrm{D}$ = variação cambial em relação ao dólar americano; e $\mathrm{R}$ = rentabilidade das instituições bancárias.

Esses dados indicam, inicialmente, que o mercado de depósitos é mais concentrado que o de créditos e o dos ativos totais, além de se mostrar menos volátil, tanto com o C4 quanto com o HHI. No caso dos parâmetros dos ativos totais e das operações de crédito, as medidas médias são relativamente próximas, com prevalência do parâmetro ativos totais no indicador $\mathrm{C} 4$ e do parâmetro operações de crédito no HHI, com a ressalva de que as medidas relativas ao mercado de crédito apresentam maior volatilidade.

Pelas medidas médias apuradas, tanto a hipótese $H_{1}$ quanto a $H_{2}$ são rejeitadas, tendo em vista que os indicadores $\mathrm{C} 4 \mathrm{e} \mathrm{HHI}$ não indicam evidências de concentração, considerando-se os parâmetros de ativos totais, operações de crédito ou depósitos bancários, de acordo com os critérios de- finidos pelas autoridades antitrustes brasileiras e norte-americanas.

Nos indicadores $\mathrm{C} 4$, mesmo nos pontos máximos, não é alcançado o limite dos $75 \%$, mas nos HHI os pontos máximos dos três parâmetros de mensuração superam o limite de 0,10 , o que caracteriza mercado com "concentração moderada". Isso indica que, seguindo os critérios das autoridades antitruste norte-americanas, durante $o$ período examinado, mesmo que eventualmente, o mercado ultrapassou o limite para ser considerado como apresentando "evidências de concentração". Para uma avaliação mais apropriada dessa questão, são demonstradas, nos Gráficos 1 e 2, as evoluções dos indicadores $\mathrm{C} 4$ e HHI, respectivamente, em relação aos parâmetros de ativos totais, operações de crédito e depósitos bancários.

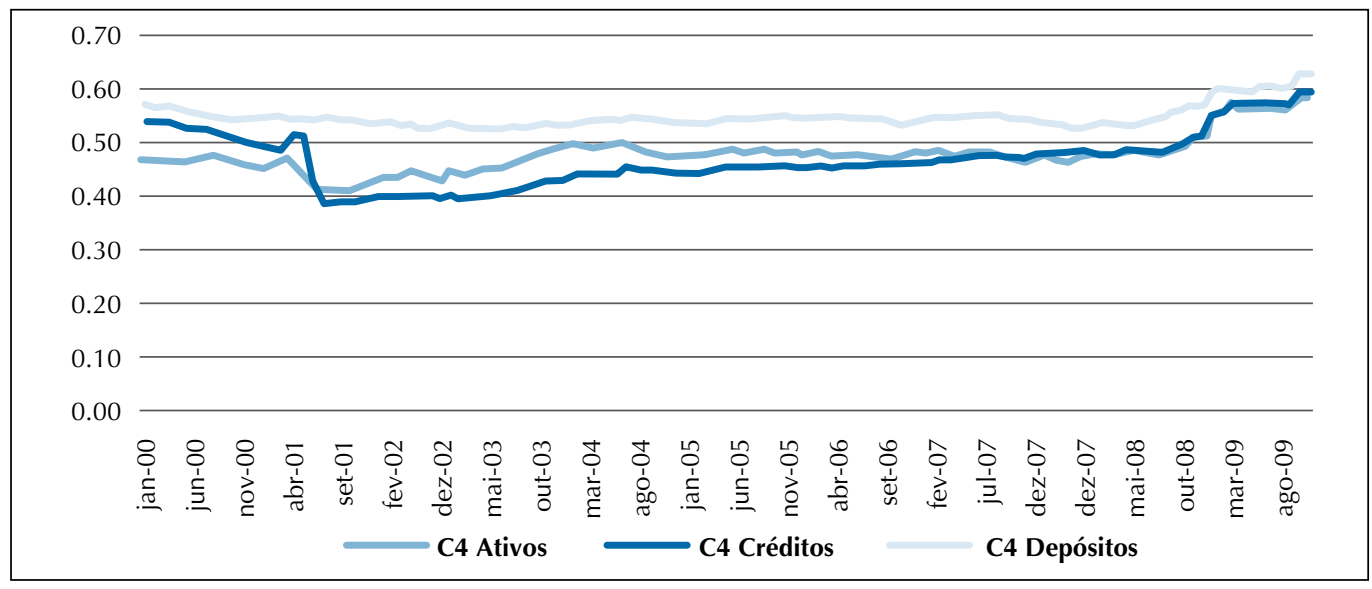

Gráfico 1 Evolução dos graus de concentração no SFN, de acordo com o C4 - jan./2000 a dez./2009 


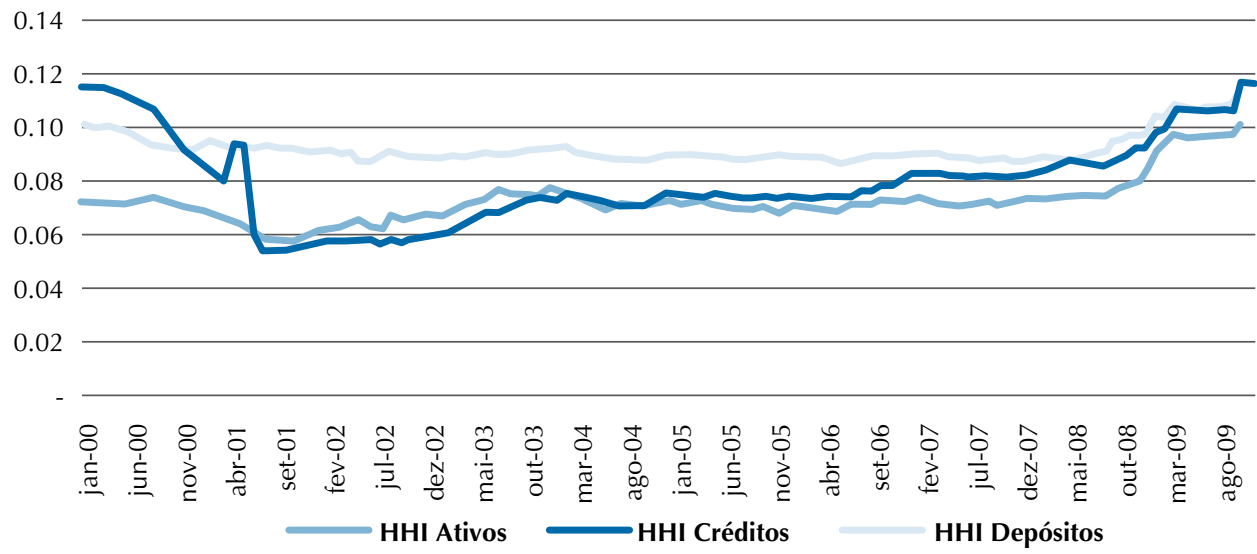

Gráfico 2 Evolução dos graus de concentração no SFN, de acordo com o HHI - jan./2000 a dez./2009

Nos dois gráficos, considerando-se o C4 ou o HHI, são detectadas duas variações mais relevantes. O movimento mais brusco ocorreu em junho/2001, quando a Caixa Econômica Federal promoveu uma série de operações no âmbito do Programa de Fortalecimento das Instituições Financeiras Federais, que resultou em forte redução de sua carteira de crédito, principalmente pela transferência de créditos para a Empresa Gestora de Ativos (Emgea). Isso se refletiu na redução dos indicadores de concentração nos parâmetros de operações de crédito e ativos totais. O outro movimento ocorreu a partir do quarto trimestre de 2008 e deveu-se a dois fatores: (i) os efeitos da crise financeira global de 2008, que tem como consequência primária o aumento da desconfiança no sistema, ocasionando uma maior concentração dos depósitos nas maiores instituições e a limitação de recursos disponíveis para operações de crédito por parte dos bancos de menor porte; e (ii) o aumento do número de atos de cisões e incorporações verificados durante o ano de 2009, conforme demonstrado na Tabela 1.

No que se refere ao indicador $\mathrm{C} 4$, os dados demonstrados no Gráfico 1 revelam que: (i) o mercado de depósitos apresenta um grau de concentração maior e mais estável que os demais; (ii) o mercado de cré- dito apresenta variações mais acentuadas no nível de concentração ao longo do período; (iii) para todos os parâmetros foi constatado um crescimento do indicador a partir do quarto trimestre de 2008, fazendo com que encerrassem o período do estudo em seu patamar mais elevado; (iv) mesmo com esse crescimento, em nenhum dos parâmetros de apuração foi alcançado o limite de 75\% estabelecido na Portaria Conjunta SEAE/SDE ${ }^{\circ}$ 50/2001. Em síntese, apesar do crescimento dos indicadores na fase final do período examinado, o que sugere a possibilidade de esse comportamento configurar-se como uma tendência, os dados analisados indicam não haver evidências de concentração, de acordo com os parâmetros definidos pelas autoridades antitrustes brasileiras, rejeitando-se a hipótese de pesquisa $H_{1}$.

No tocante aos indicadores $\mathrm{HHI}$, conforme Gráfico 2, o comportamento é relativamente equivalente aos do $\mathrm{C} 4$, ou seja: (i) o mercado de depósitos apresenta níveis de concentração mais elevados e relativamente mais estáveis que os ativos totais e as operações de crédito; (ii) o indicador do mercado de créditos apresenta maior volatilidade; (iii) os indicadores referentes aos três parâmetros apresentam crescimento significativo a partir do quarto trimestre de 2008, encerrando 
o ano de 2009 em seus pontos mais acentuados. A diferença dá-se, no entanto, em relação aos critérios para se julgar se o mercado apresenta ou não evidências de concentração. Enquanto o crescimento dos indicadores C4 não foi suficiente para se alcançar o limite do que seria considerado, pelos critérios estabelecidos nas normas brasileiras, um mercado concentrado, no caso do HHI a evolução verificada na fase final do período de análise fez com que os indicadores ultrapassassem o limite para se considerar um mercado como não concentrado.

Assim, constata-se que, em praticamente todo o período examinado, não há evidências de concentração no mercado bancário brasileiro, em relação aos parâmetros de ativos totais, créditos ou depósitos, de acordo com os critérios estabelecidos no Horizontal Merger Guidelines, editados pelo Departamento de Justiça dos Estados Unidos, rejeitando-se a hipótese de pesquisa $H_{2}$. Os dados do final do período de exame revelam, porém, que a indústria bancária está situada no nível de "concentração moderada", em todos os parâmetros estudados, mais especialmente em relação às operações de crédito e aos depósitos bancários, o que corrobora a hipótese $H_{2}$.

Como ressalva, há que se destacar que a apuração dos graus de concentração se deu com o uso de dados das instituições finan- ceiras individuais e não dos conglomerados - definidos como o conjunto de instituições financeiras que consolidam suas demonstrações contábeis. Aliás, essa pode ser a razão para a incompatibilidade entre o C4 apurado em relação ao parâmetro dos ativos totais e os dados do estudo do Banco Mundial referentes ao mercado brasileiro, sintetizados na Tabela 3 , que aponta um indicador $\mathrm{C} 3$ relativo aos ativos totais de 0,8324 no final de 2008 , quando o C4, no presente estudo no mesmo período, foi de 0,5041. Muito provavelmente tal fato se deve à utilização de dados consolidados.

\subsection{Procedimento econométrico - relação entre rentabilidade e concentração}

A segunda etapa da análise empírica consiste no estudo da relação do grau de concentração da indústria bancária brasileira e da participação de cada instituição no mercado com a rentabilidade das instituições financeiras. Para o teste das hipóteses de pesquisa $\mathrm{H}_{3}$ e $H_{4}$, foi testado o modelo (3) considerando os parâmetros dos ativos totais das instituições, das operações de crédito e dos depósitos bancários como referência para a apuração das medidas de concentração e de participação no mercado. Os resultados dos testes com dados em painel, com efeitos fixos seccionais, são demonstrados na Tabela5.

Tabela 5 Resultados dos testes do modelo (3) - estatísticas $t$ entre parênteses

\begin{tabular}{|c|c|c|c|c|c|c|}
\hline \multirow{2}{*}{ Variáveis independentes } & \multicolumn{2}{|c|}{ Parâmetro: Ativos } & \multicolumn{2}{|c|}{ Parâmetro: Op. Créditos } & \multicolumn{2}{|c|}{ Parâmetro: Depósitos } \\
\hline & Var. Dep.: $R$ & Var. Dep.: $R$ & Var. Dep.: $R$ & Var. Dep.: $R$ & Var. Dep.: $R$ & Var. Dep.: $R$ \\
\hline \multirow{3}{*}{ Const } & 0,00233 & 0,0025 & 0,00244 & 0,00157 & 0,00567 & 0,00423 \\
\hline & $(3,851)$ & $(6,001)$ & $(6,153)$ & $(6,527)$ & $(5,936)$ & $(6,983)$ \\
\hline & $* * *$ & $* * *$ & $* * *$ & $* * *$ & $* * *$ & $* * *$ \\
\hline \multirow{3}{*}{ C4 } & $-0,00138$ & & $-0,00278$ & & $-0,00791$ & \\
\hline & $(-1,240)$ & & $(-3,989)$ & & $(-4,785)$ & \\
\hline & & & $* * *$ & & $* * *$ & \\
\hline \multirow{3}{*}{$\mathrm{HHI}$} & & $-0,01019$ & & $-0,00627$ & & $-0,03064$ \\
\hline & & $(-2,284)$ & & $(-3,023)$ & & $(-5,221)$ \\
\hline & & $* *$ & & $* * *$ & & $* * *$ \\
\hline
\end{tabular}


continuação

\begin{tabular}{|c|c|c|c|c|c|c|}
\hline \multirow{2}{*}{ Variáveis independentes } & \multicolumn{2}{|c|}{ Parâmetro: Ativos } & \multicolumn{2}{|c|}{ Parâmetro: Op. Créditos } & \multicolumn{2}{|c|}{ Parâmetro: Depósitos } \\
\hline & Var. Dep.: $R$ & Var. Dep.: $R$ & Var. Dep.: $R$ & Var. Dep.: $R$ & Var. Dep.: $R$ & Var. Dep.: $R$ \\
\hline \multirow{3}{*}{$P$} & $-0,01515$ & $-0,01489$ & 0,00363 & 0,00329 & $-0,01185$ & $-0,01252$ \\
\hline & $(-3,328)$ & $(-3,271)$ & $(1,214)$ & $(1,099)$ & $(-2,792)$ & $(-2,959)$ \\
\hline & $* * *$ & $* * *$ & & & $* * *$ & *** \\
\hline \multirow{3}{*}{ J } & 0,00347 & 0,0024 & 0,00437 & 0,00514 & 0,00327 & 0,00242 \\
\hline & $(2,458)$ & $(1,605)$ & $(3,209)$ & $(3,877)$ & $(2,450)$ & $(1,750)$ \\
\hline & $* *$ & & $* * *$ & $* * *$ & ** & * \\
\hline \multirow{3}{*}{$E$} & 0.01176 & 0,0121 & 0,01288 & 0,01266 & 0,01236 & 0,01203 \\
\hline & $(4,323)$ & $(4,449)$ & $(4,752)$ & $(4,668)$ & $(4,412)$ & $(4,285)$ \\
\hline & $* * *$ & $* * *$ & $* * *$ & $* * *$ & $* * *$ & *** \\
\hline \multirow{3}{*}{$D$} & 0.00162 & 0,00152 & 0,00182 & 0,00191 & 0,00212 & 0,00227 \\
\hline & $(2,862)$ & $(2,701)$ & $(3,269)$ & $(3,438)$ & $(3,708)$ & $(3,966)$ \\
\hline & *** & $* * *$ & $* * *$ & $* * *$ & $* * *$ & *** \\
\hline NNo observações: & 18.755 & 18.755 & 17.815 & 17.815 & 17.630 & 17.630 \\
\hline$R^{2}:$ & 0,1185 & 0,1187 & 0,1104 & 0,1101 & 0,1052 & 0,1054 \\
\hline F-stat: & 12,1702 & 12,1883 & 10,6618 & 10,6255 & 10,1376 & 10,1621 \\
\hline DW-stat: & 1,8113 & 1,8114 & 1,8460 & 1,8458 & 1,8387 & 1,8382 \\
\hline Chow-test: & 7,7600 & 7,7700 & 6,8000 & 6,7900 & 5,6100 & 5,5900 \\
\hline Hausman & 19,4522 & 18,2963 & 9,9207 & 9,4219 & 10,3516 & 10,3998 \\
\hline
\end{tabular}

Nota 1: Modelo empregado (equação 3): $R_{i, t}=\beta_{0}+\beta_{1} C_{t}+\beta_{2} P_{i, t}+\beta_{3} J_{t}+\beta_{4} E_{t}+\beta_{5} D_{t}+\varepsilon_{i, t^{\prime}}$ sendo que a variável $C$, representativa do grau de concentração do mercado, assume os indicadores $C 4$ ou $\mathrm{HHI}$.

Nota 2: Legenda para a relevância dos parâmetros: a $99 \%\left(^{(* *)}\right.$; a $95 \%(* *)$; e a $90 \%\left(^{*}\right)$.

Testes de robustez e análise da significância do modelo

Como pré-condição para assegurar a robustez dos resultados dos testes relativos ao modelo (3), foram realizados os testes de raízes unitárias, para verificar a condição de es- tacionariedade das séries. Para esse fim, foram utilizados os testes Im, Pesaran e Shin (I.P.S.), ADF-Fisher e PP-Fisher para as séries $R S A, P_{a P}$ $P_{c r}, P_{d p}, J$, E e D, conforme Tabela 6, rejeitandose a hipótese nula da existência de raízes unitárias, com p-valor 0,0000 em todos os casos.

Tabela 6 Resultados dos testes de raiz unitária das séries do modelo (3)

\begin{tabular}{c|r|r|r|r|r|r|r}
\hline Teste & \multicolumn{1}{c|}{ RSA } & \multicolumn{1}{c|}{$P_{a t}$} & \multicolumn{1}{c|}{$P_{c r}$} & \multicolumn{1}{c|}{$P_{d p}$} & \multicolumn{1}{c}{ J } & \multicolumn{1}{c}{$D$} \\
\hline I.P.S. & $-95,81$ & $-2,79$ & $-3,66$ & $-3,30$ & $-10,68$ & $-44,62$ & $-66,42$ \\
\hline ADF & 7981,43 & 647,57 & 658,88 & 655,56 & 618,62 & 2818,24 & 4923,13 \\
\hline PP & 9448,48 & 897,88 & 721,47 & 729,89 & 1544,80 & 3058,65 & 14242,60 \\
\hline
\end{tabular}

No caso dos indicadores de concentração HHI e C4, as estatísticas dos testes não permitem a rejeição da hipótese nula da presença de raiz unitária. Mesmo assim, o risco de regressões espúrias é eliminado pelo fato de as demais variáveis explicativas e, principalmente, a variável dependente não registrarem raízes unitárias. Ademais, não obstante os resultados dos testes, não é razoável se admitir a possibilidade do crescimento contínuo e permanente da variável, tendo em vista que isso conduziria a um processo de monopólio, o que, objetivamente, não é o caso. Uma razão para esse resultado dos testes pode ser o 
tempo considerado na análise, dez anos, que parece ser relativamente curto para a reversão à média.

Para avaliar a existência de efeitos individuais, o que justifica o uso dos dados em painel, foi realizado o teste sugerido por Baltagi (2008), que recebe a denominação de Chow test pela similaridade com o teste de quebra estrutural. Conforme estatísticas incorporadas na Tabela 5, foi rejeitada a hipótese nula de que os resultados apurados sem a consideração da heterogeneidade individual seriam apropriados, demonstrando a relevância da utilização dos dados em painel para o provimento de evidências com maior poder informacional.

Para a definição do método de dados em painel a ser utilizado, modelos fixos ou aleatórios, foi realizado o teste de Hausman para as seis especificações dos testes, conforme destacado na Tabela 5. Os resultados demonstraram que, no caso de se utilizar o parâmetro dos ativos totais, a hipótese nula de que os estimadores dos modelos de efeitos fixos e de efeitos aleatórios não diferem substancialmente é rejeitada, tornando imprópria a utilização do método com efeitos aleatórios. Por essa razão, é utilizado o método com efeitos fixos, tendo em vista que oferece parâmetros consistentes em todas as condições analisadas. Além do mais, segundo Gujarati (2006), a premissa subjacente ao modelo com efeitos aleatórios é que os erros são extrações aleatórias de uma população muito maior, o que não é o caso do presente estudo, que considera o conjunto das instituições bancárias de interesse.

Para se prevenir do risco de heteroscedaticidade nos resíduos, foi usado o método cross section weights, que estima parâmetros robustos assumindo a presença de heteroscedasticidade seccional. Adicionalmente, as estatísticas do teste Durbin-Watson destacadas na Tabela 5 demonstram não haver evidências de autocorrelação nos resíduos, a 5\%.
Assim, assumindo-se a normalidade dos resíduos, tem-se que esses são normalmente distribuídos, com média zero e variância constante e ausência de autocorrelação, ou seja, $\varepsilon_{i, t} \sim N\left(E\left(\varepsilon_{i, t}\right)=0, \operatorname{Var}\left(\varepsilon_{i, t}\right)=\sigma^{2}\right.$ e $\left.\operatorname{Cor}\left(\varepsilon_{i} \varepsilon_{j}\right)=0\right)$.

$O$ coeficiente de determinação da regressão, $R^{2}$, situa-se, nas seis especificações testadas, entre 0,1052 e 0,1187 , conforme destacado na Tabela 5, sugerindo que variáveis relevantes para a explicação da rentabilidade das instituições estão omitidas no modelo, o que não compromete os propósitos específicos do estudo: avaliar a relação entre a rentabilidade e o grau de concentração e de participação no mercado.

Por fim, tendo em vista o comportamento dos indicadores $\mathrm{C} 4$ e $\mathrm{HHI}$ destacado na seção 4.1, notadamente quanto à variação mais acentuada a partir do quarto trimestre de 2008, foi realizado o predictive failure test, sugerido por Brooks (2002) e utilizado por Fletcher, Mangan e Raeburn (2004) para identificar quebras estruturais em modelos de precificação de imóveis. Os resultados demonstram que a hipótese nula da estabilidade dos parâmetros para o período não pode ser rejeitada, demonstrando não haver evidências de quebra estrutural na relação estudada, o que representa um elemento de robustez das evidências obtidas no estudo.

\section{Análise dos resultados das regressões}

Considerando os resultados apurados em função dos ativos totais, constata-se que o grau de concentração $\mathrm{C} 4$ não é relevante para explicar a rentabilidade das instituições, representada pelo retorno sobre os ativos. No caso do indicador HHI, foi encontrada relação estatisticamente relevante com a medida de performance, mas, ao contrário do previsto, o sinal encontrado é negativo. Assim, em ambas as situações, utilizando-se C4 ou HHI, a hipótese de pesquisa $H_{3}$ não é confirmada.

Em relação à participação de cada ins- 
tituição no mercado, foi constatada relação estatisticamente relevante com o nível de rentabilidade, mas com sinal negativo, inverso ao esperado. Assim, a hipótese $H_{4}$, que se sustenta nas premissas do paradigma HCP, não é confirmada. Ao contrário, os dados demonstram que se aplica ao caso a hipótese HEE, oferecendo indícios de que a conquista de mercado se dá por instituições mais eficientes.

Quanto às variáveis de controle, foram encontradas relações positivas e estatisticamente significantes do retorno sobre os ativos das instituições com o nível de taxa de juros real da economia, com a variação cambial e com o nível de atividade econômica. A exceção se dá em relação à variável representativa dos juros reais da economia, quando é testado o $\mathrm{HHI}$, em que o parâmetro, apesar de também ser positivo, registrou um p-valor de 0,1085 , evidência de pouca relevância estatística.

Ao se utilizar o parâmetro das operações de crédito, os resultados demonstram que os graus de concentração do mercado, C4 ou HHI, apresentam relação estatisticamente relevante com a performance das instituições bancárias. A hipótese $H_{3}$, porém, não é corroborada, tendo em vista que, ao contrário do inicialmente previsto, a relação encontrada é negativa.

No que se refere à participação das instituições no mercado de crédito, a variável não se mostrou estatisticamente significante para explicar o nível de rentabilidade das instituições bancárias no Brasil, medida pelo retorno sobre os ativos, rejeitando-se $H_{4}$.

No tocante às variáveis de controle, os resultados são equivalentes aos encontrados quando foi utilizado o parâmetro dos ativos totais, ou seja, relevância das variáveis taxa real de juros, variação cambial do dólar americano e nível de atividade econômica para explicar o retorno sobre ativos das instituições bancárias, entre 2000 e 2009, todas com sinal positivo.
Utilizando-se os depósitos bancários para mensurar as variáveis explicativas de interesse, os resultados demonstram que tanto os graus de concentração, C4 ou HHI, quanto a participação de cada entidade nesse mercado são estatisticamente relevantes para explicar a rentabilidade das instituições. Mas, ao contrário do previsto em $H_{3}$ e $H_{4}$, os coeficientes encontrados apresentam sinais negativos. De acordo com esses resultados, quando ocorre um aumento da concentração no mercado de depósitos, a performance média das instituições financeiras é reduzida, indicando que a conquista de mercado se dá por instituições mais eficientes, conforme prevê a HEE. São rejeitadas, portanto, as hipóteses $H_{3}$ e $H_{4}$, baseadas na premissa de que o aumento da concentração leva as entidades a atuar oligopolisticamente.

Quanto às variáveis de controle, repetiram-se os achados dos testes que consideraram os parâmetros de ativos totais e de operações de crédito, tanto quanto à relevância como ao sinal, em relação às medidas relativas ao nível de taxa de juros real da economia, à variação cambial e ao nível de atividade econômica para explicar o retorno sobre os ativos dos bancos.

\section{Síntese dos resultados dos testes}

Em resumo, os testes demonstram que são rejeitadas as hipóteses de pesquisas $H_{3}$ e $H_{4}$, formuladas com base nos preceitos do paradigma HCP - que pressupõe que maior concentração do mercado causa menor competição e resulta em maior rentabilidade dos maiores bancos, por esses agirem oportunisticamente - pela não significância das variáveis de interesse ou pela relevância estatística com sinal negativo. Esse foi o caso de todas as situações decorrentes da combinação dos testes que consideram os indicadores de concentração com os parâmetros de análise (ativos, créditos e depósitos), conforme Quadro 2. 
Quadro 2 Síntese dos resultados dos testes do modelo (3)

\begin{tabular}{|l|c|c|c|c|}
\hline \multirow{2}{*}{ Parâmetro de análise } & \multicolumn{2}{|c|}{ Considerando o indicador C4 } & \multicolumn{2}{c|}{ Considerando o indicador HHI } \\
\cline { 2 - 5 } & $\mathbf{C 4}$ & $\boldsymbol{P} \mathbf{H}$ & $\boldsymbol{P}$ \\
\hline Ativos totais & Não significante & $\begin{array}{c}\text { Significante } \\
\text { (negativo) }\end{array}$ & $\begin{array}{c}\text { Significante } \\
\text { (negativo) }\end{array}$ & $\begin{array}{c}\text { Significante } \\
\text { (negativo) }\end{array}$ \\
\hline Operações de créditos & $\begin{array}{c}\text { Significante } \\
\text { (negativo) }\end{array}$ & Não significante & $\begin{array}{c}\text { Significante (ne- } \\
\text { gativo) }\end{array}$ & Não significante \\
\hline Depósitos bancários & $\begin{array}{c}\text { Significante } \\
\text { (negativo) }\end{array}$ & $\begin{array}{c}\text { Significante } \\
\text { (negativo) }\end{array}$ & $\begin{array}{c}\text { Significante } \\
\text { (negativo) }\end{array}$ & $\begin{array}{c}\text { Significante } \\
\text { (negativo) }\end{array}$ \\
\hline
\end{tabular}

Portanto, a previsão inicial de que a maior concentração do mercado bancário seria uma das causas determinantes para a rentabilidade das instituições financeiras não encontra suporte nos testes realizados. São obtidas evidências de que a HEE se aplica mais adequadamente ao SFN, ou seja, sem entrar no mérito de que a rentabilidade dos bancos seja alta ou baixa, as evidências obtidas demonstram que um movimento no sentido de aumentar a concentração não tem se traduzido em uma maior medida de retorno dos integrantes do mercado.

Cabe ressaltar, entretanto, que as evidências obtidas nesse estudo quanto à relação entre concentração e performance das instituições, medida pelo retorno sobre os ativos, não pode ser automaticamente estendida ao spread bancário, tendo em vista que é possível se encontrar resultados distintos, conforme evidenciado por Brock e Franken (2002).

Em relação às variáveis de controle, foram confirmadas as relações positivas entre a rentabilidade das instituições bancárias e a taxa de juros da economia (J), o nível de atividade econômica (E) e a variação cambial do dólar americano (D), conforme previsto preliminarmente na seção 3.3.

Análise do risco de multicolinearidade

Como forma de avaliar a robustez dos achados, foi verificada a existência de cor- relação entre as variáveis explicativas dos modelos testados, que poderiam refletir problemas de alto grau de multicolinearidade - podendo resultar, inclusive, em alteração dos sinais dos coeficientes das variáveis de interesse - foi elaborada a Matriz de Correlação de Pearson, conforme Tabela 7.

Tabela 7 Matriz de Correlação de Pearson - Regressores do modelo (3) - p-valor entre parêntesess

Parâmetro: ativos totais

\begin{tabular}{|c|c|c|c|c|c|c|}
\hline & C4 & HHI & $P$ & J & $E$ & $D$ \\
\hline C4 & 1 & & & & & \\
\hline HHI & $\mathrm{n} / \mathrm{a}$ & 1 & & & & \\
\hline$P$ & $\begin{array}{r}, 004 \\
(, 597)\end{array}$ & $\begin{array}{r}, 004 \\
(, 600)\end{array}$ & 1 & & & \\
\hline$J$ & $\begin{array}{r}-, 549 \\
(, 000)\end{array}$ & $\begin{array}{l}-, 614 \\
(, 000)\end{array}$ & $\begin{array}{l}-, 003 \\
(, 721)\end{array}$ & 1 & & \\
\hline$E$ & $\begin{array}{r}, 151 \\
(, 100)\end{array}$ & $\begin{array}{r}, 154 \\
(, 094)\end{array}$ & $\begin{array}{r}, 001 \\
(, 902)\end{array}$ & $\begin{array}{r}-, 078 \\
(, 396)\end{array}$ & 1 & \\
\hline$D$ & $\begin{array}{r}-, 230 \\
(, 011)\end{array}$ & $\begin{array}{l}-, 207 \\
(, 023)\end{array}$ & $\begin{array}{r}-, 001 \\
(, 924)\end{array}$ & $\begin{array}{r}, 077 \\
(, 404)\end{array}$ & $\begin{array}{l}-, 088 \\
(, 340)\end{array}$ & 1 \\
\hline
\end{tabular}

Parâmetro: operações de crédito

\begin{tabular}{|c|c|c|c|c|c|c|}
\hline & C4 & HHI & $P$ & $J$ & $E$ & $D$ \\
\hline C4 & 1 & & & & & \\
\hline HHI & $\mathrm{n} / \mathrm{a}$ & 1 & & & & \\
\hline$P$ & $\begin{array}{r}, 002 \\
(, 782)\end{array}$ & $\begin{array}{r}, 001 \\
(, 893)\end{array}$ & 1 & & & \\
\hline$J$ & $\begin{array}{l}-, 460 \\
(, 000)\end{array}$ & $\begin{array}{l}-, 400 \\
(, 000)\end{array}$ & $\begin{array}{l}-, 003 \\
(, 600)\end{array}$ & 1 & & \\
\hline$E$ & $\begin{array}{r}, 117 \\
(, 202)\end{array}$ & $\begin{array}{r}, 117 \\
(, 203)\end{array}$ & $\begin{array}{r}, 002 \\
(, 824)\end{array}$ & $\begin{array}{r}-, 078 \\
(, 396)\end{array}$ & 1 & \\
\hline$D$ & $\begin{array}{l}-, 117 \\
(, 204)\end{array}$ & $\begin{array}{r}-, 090 \\
(, 329)\end{array}$ & $\begin{array}{r}-, 002 \\
(, 745)\end{array}$ & $\begin{array}{r}, 077 \\
(, 404)\end{array}$ & $\begin{array}{l}-, 088 \\
(, 340)\end{array}$ & 1 \\
\hline
\end{tabular}


Parâmetro: depósitos

\begin{tabular}{c|r|r|r|r|r|r}
\hline & \multicolumn{1}{c|}{$\boldsymbol{C 4}$} & \multicolumn{1}{c|}{$\boldsymbol{H} \boldsymbol{H} \boldsymbol{c}$} & $\boldsymbol{P}$ & $\boldsymbol{J}$ & $\boldsymbol{E}$ & $\boldsymbol{D}$ \\
\hline $\boldsymbol{C} 4$ & 1 & & & & & \\
\hline $\boldsymbol{H} \boldsymbol{H I}$ & $\mathrm{n} / \mathrm{a}$ & 1 & & & & \\
\hline $\boldsymbol{P}$ &, 002 &, 000 & 1 & & & \\
\hline $\boldsymbol{J}$ & $\begin{array}{r}-, 370) \\
(, 979\end{array}$ & $\begin{array}{r}-, 440 \\
(, 000)\end{array}$ & $\begin{array}{r}-, 003 \\
(, 668)\end{array}$ & 1 & & \\
\hline $\boldsymbol{E}$ &, 031 &, 005 &, 002 &,- 078 & 1 & \\
\hline $\boldsymbol{D}$ & $(, 733)$ & $(, 957)$ & $(, 798)$ & $(, 396)$ & & \\
\hline &,- 089 &,- 041 &,- 002 &, 077 &,- 088 & 1 \\
$(, 656)$ & $(, 820)$ & $(, 404)$ & $(, 340)$ & \\
\hline
\end{tabular}

Em que: $\mathrm{C} 4$ = índice de participação dos quatro maiores bancos; $\mathrm{HHI}=$ índice Herfildahl-Hirschman; $\mathrm{P}=$ participação de cada banco no mercado; J = taxa de juros real da economia; $\mathrm{E}=$ indicador de atividade; e D = variação cambial em relação ao dólar americano.

Os resultados demonstram que, considerando as seis aplicações do modelo (3.3) - combinando parâmetros de ativos totais, operações de crédito e depósitos com as medidas $\mathrm{HHI}$ e C4 para mensurar o grau de concentração do mercado - foram constatadas correlações entre a taxa básica de juros (J) e as medidas de concentração (C4 ou HHI). Também foi constatada correlação, embora em menor grau de significância, entre a variação cambial (D) e os graus de concentração (C4 ou HHI), mas apenas ao se considerar o parâmetro de ativos totais.

Esses dados, basicamente em relação à utilização da variável J, podem indicar problemas de multicolinearidade com as medidas de concentração. Para evitar o risco de distorções nos resultados das variáveis de interesse, foram elaboradas simulações adicionais com o modelo (3.3) com a exclusão paulatina das variáveis de controle - primeiro desconsiderando a variável J, depois J e D e, finalmente, excluindo J, D e E. Por simplificação e limitação de espaço, são transcritos, na Tabela 8 (anexos), apenas os resultados das simulações com a exclusão de todas as variáveis de controle, permanecendo apenas as variáveis de interesse: $\mathrm{C} 4$ ou $\mathrm{HHI}$ e $\mathrm{P}$.

Em todas as simulações realizadas, os sinais dos parâmetros das variáveis de interesse são equivalentes ao verificado no modelo original, sintetizados no Quadro 2, exceto pelo fato de que o indicador $\mathrm{C} 4$ apurado com base nos ativos totais, que não foi relevante no modelo básico, apresentou relevância estatística no modelo reduzido, com sinal negativo. Os resultados demonstram que a exclusão das variáveis de controle melhora ainda mais a relevância das variáveis de interesse, eliminando-se o risco de que as evidências originais fossem decorrentes do risco de multicolinearidade.

\section{Simulações adicionais - ampliação do modelo com novas variáveis de controle}

Também tendo em vista que os resultados encontrados contrariaram as expectativas intuitivas iniciais que deram suporte à formulação das hipóteses de pesquisas, bem como o fato de o apurado nos testes com o modelo básico sugerirem a possibilidade de variáveis omitidas, foram realizados novos testes, como forma de confirmar a consistência dos achados.

Para isso, somando-se e em sentido inverso às simulações destacadas no item anterior - que simplificou o modelo básico com a exclusão das variáveis de controle - foram incorporadas ao modelo (3.3) mais três variáveis explicativas de controle: a variação do Ibovespa (I); a nacionalidade do capital de controle (Nac) - variável do tipo dummy, assumindo 1 para os bancos nacionais e 0 para as instituições estrangeiras; e o tipo de origem do controle (Cont) - variável do tipo dummy, assumindo 1 para os bancos estatais e 0 para as instituições privadas. Assim, é testado o modelo (5):

$$
\begin{aligned}
R_{i, t}= & \beta_{0}+\beta_{1} C_{t}+\beta_{2} P_{i, t}+\beta_{3} J_{t}+\beta_{4} E_{t}+\beta_{5} D_{t}+\beta_{6} I_{t} \\
& +\beta_{7} \mathrm{Nac}_{i, t}+\beta_{8} \text { Cont }_{i, t}+\varepsilon_{i, t}
\end{aligned}
$$

Os resultados, transcritos na Tabela 9 (anexos), confirmam as evidências obtidas em relação à significância estatística das variáveis de concentração e de participação das instituições no mercado, considerando 
os parâmetros de ativos totais, operações de crédito e depósitos bancários, sintetizados no Quadro 2, inclusive quanto ao sinal negativo.

Os resultados desses dois conjuntos de testes adicionais - considerando a exclusão ou a ampliação das variáveis de controle - reforçam os achados do modelo básico tanto quanto à relevância estatística dos indicadores de concentração e de participação no mercado como ao sinal dos seus parâmetros, reforçando-se as evidências obtidas inicialmente de que a hipótese de estrutura eficiente se aplica mais adequadamente ao SFN. Em relação ao $R^{2}$, as novas especificações testadas não apresentam maiores avanços - em seu maior nível, alcança 0,1328. Considerando, porém, a limitação de propósito do presente estudo, estende-se não haver comprometimento dos achados, tendo em vista a consistência da relevância e dos sinais das variáveis de interesse nas diversas simulações.

\section{CONSIDERAÇÕES FINAIS}

Este estudo teve o objetivo de avaliar a evolução do grau de concentração da indústria bancária brasileira, além de verificar se há relação entre o nível de rentabilidade das instituições bancárias e o grau de concentração do setor, considerando os parâmetros de ativos totais, operações de crédito e depósitos bancários, no período de janeiro/2000 a dezembro/2009.

Os testes realizados quanto ao grau de concentração tiveram por base as referências metodológicas adotadas pelas autoridades antitruste do Brasil e dos EUA para avaliação e julgamento dos atos de concentração econômica. De acordo com os critérios brasileiros, não foram encontradas evidências de concentração no SFN, tendo em vista que o indicador C4 não ultrapassou o limite de 75\% do mercado em nenhum dos três parâmetros considerados, não obstante a evolução do indicador a partir do quarto trimestre de 2008, rejeitando-se a hipótese de pesquisa $H_{1}$, que previa evidências de concentração no mercado, de acordo com esses critérios.

Ao se utilizarem os parâmetros instituídos pelas autoridades dos EUA, que utiliza o HHI como referência, foi constatado que, em praticamente todo o período da amostra, não foram identificadas evidências de concentração do mercado bancário brasileiro - em relação aos ativos totais, operações de crédito e depósitos bancários. Os resultados demons- tram, porém, que, no final do período da amostra, os indicadores ultrapassam o limite a ser considerado como mercado de "concentração moderada" em todos os parâmetros, mais especialmente em relação às operações de crédito e aos depósitos bancários. Assim, $\mathrm{H}_{2}$ é rejeitada ao se considerar o comportamento médio entre 2000 e 2009 , mas não em relação aos dados do final do período de exame. Em suma, pelos critérios instituídos pelas autoridades americanas, o mercado bancário brasileiro apresenta, no final do período avaliado, evidências de concentração, conforme previsto em $\mathrm{H}_{2}$, embora em nível moderado.

A segunda parte dos testes empíricos consiste na verificação da relação do grau de concentração do SFN e da participação de cada instituição no mercado com a rentabilidade dos bancos, medida pelo retorno sobre os ativos. Foram formuladas duas hipóteses de pesquisa, $H_{3}$ e $H_{4}$, suportadas nos preceitos do paradigma estrutura - conduta - performance, que pressupõe que a menor competição decorrente de uma maior concentração resulta em maior rentabilidade das instituições bancárias, tendo em vista que, em mercados mais concentrados, as empresas, notadamente as maiores, comportam-se oligopolisticamente.

Os testes foram realizados considerando os dois tipos de indicadores de concentração, C4 e HHI, em relação aos parâmetros de ati- 
vos totais, operações de crédito e depósitos bancários. Os resultados em relação aos três parâmetros são distintos: (i) utilizando os ativos totais, não foi encontrada relação estatisticamente significante da rentabilidade das instituições com o grau de concentração C4, mas foi detectada relação negativa relevante com o nível de participação das instituições no mercado e com a concentração do mercado medida pelo HHI; (ii) usando o parâmetro das operações de crédito, foi verificada relação significante da rentabilidade das instituições com os graus de concentração C4 e HHI, mas não com a participação dos bancos no mercado e (iii) adotando-se o parâmetro dos depósitos bancários, foram constatadas relações negativas estatisticamente relevantes do nível de rentabilidade das instituições tanto com os graus de concentração C4 ou HHI quanto com a participação das instituições no mercado.

Em síntese, os resultados não corroboram as hipóteses de pesquisa $H_{3}$ e $H_{4}$ em nenhuma das combinações de testes realizadas, seja pela insignificância dos parâmetros ou pelo sinal negativo, quando os parâmetros são relevantes. Não são confirmadas, portanto, as previsões iniciais de que a maior concentração do mercado bancário brasileiro acarretaria um aumento na rentabilidade das instituições financeiras, conforme preceitua a HCP. Ao contrário, foram obtidas evidências de que a HEE se aplica mais adequadamente ao SFN. Isso não significa um juízo de valor sobre o nível de rentabilidade e nem sobre o grau de concentração, mas apenas que os testes demonstram que um movimento de aumento na concentração não tem se traduzido em maiores medidas de retorno sobre os ativos, por parte das instituições.

Como limitações, há que se ressaltar, inicialmente, que as medidas de concentração utilizadas no estudo não consideram o conceito de conglomerado, sendo cada instituição considerada individualmente. Além disso, as evidências obtidas quanto à relação das medidas de concentração com a rentabilidade não podem ser automaticamente estendidas ao spread bancário, tendo em vista que é possível se encontrarem resultados distintos, como demonstrou o estudo de Brock e Franken (2002).

Por fim, a título de sugestões para futuras pesquisas, recomenda-se a avaliação dos graus de concentração utilizando-se o conceito de conglomerado, que pode apresentar conclusões diferenciadas, inclusive quanto à classificação da situação do mercado bancário brasileiro, bem como a utilização de outras medidas de performance, que não o retorno sobre os ativos, para verificar se persiste a não corroboração da hipótese estrutura - conduta-performance, como no presente estudo.

\section{Referências}

ALENCAR, Leonardo S.; LEITE, Daniel B.; FERREIRA, Sérgio G. Spread bancário: um estudo cross-country. Relatório de Economia Bancária e Crédito, 2007. Banco Central do Brasil. Disponível em: <www.bcb.gov. br/?SPREAD>. Acesso em: 29 jun. 2010.

ARAÚJO, Luiz A. D’Ávila; JORGE NETO, Paulo de M. Risco e competição bancária no Brasil. Revista Brasileira de Economia, Rio de Janeiro, v. 61, n. 2, abr./Jul. 2007, p.175-200.

BALTAGI, B. H. Econometric analysis of panel data. 4 ed. West Sussex, UK: John Wiley, 2008.

BECK, Thorsten; DEMIRGÜÇ-KUNT, Asli; LEVINE, Ross. A new database on financial development and structure. June, 1999 (updated April 2010). Disponível em: <http://econ.worldbank.org >. Acesso em 30 jun. 2010 .
Bank Concentration and crises. SSRN papers, August, 2003. Disponível em: <http://papers.ssrn. com $/$ sol3/ papers.cfm?abstract_id $=432081>$. Acesso em: 30 jun. 2010 .

. Financial institutions and markets across countries and over time: data and analysis. May, 2009. Disponível em: <http://econ.worldbank.org>. Acesso em: 30 jun. 2010.

BELAISCH, Agnès. Do brazilian Banks compete? IMF Working Paper, WP/03/113, May 2003. Disponível em: <www.imf.org/external/pubs/ft/wp/2003/wp03113.pdf>. Acesso em: 7 jul. 2010.

BROCK, Phil; FRANKEN, Helmut. Bank interest margins meet interest rate spreads: how good is balance sheet data for analyzing the cost of financial intermediation? April, 2002. Disponível em: <www.bcentral.cl/eng/studies/ 
working-papers/pdf/dtbc456.pdf >. Acesso em: 30 jun. 2010.

BROOKS, Chris. Introductory econometrics for finance. Cambridge (UK): Cambridge Press, 2002.

CARVALHO, Fernando J. C. Estrutura e padrões de competição no sistema bancário brasileiro: uma hipótese para investigação e alguma evidência preliminar.

In: PAULA, Luiz F; OREIRO, José L. (Org.) Sistema Financeiro: uma análise do setor bancário brasileiro. Rio de Janeiro: Elsevier, 2007, Cap. 5.

CHOI; Sungho; KOTROZO, Jarrett. Diversification, bank risk and performance: a cross country comparison. SSRN papers, Oct. 2006. Disponível em: <papers.ssrn.com/ sol3/papers.cfm?abstract_id=1013430 $>$. Acesso em: 30 jun. 2010.

CLAESSENS, Stijn; LAEVEN, Luc. What drives bank competition? Some international evidence. Journal of Money, Credit, and Banking, n. 36, 2004. p. 563-583. COUTO, Rodrigo Luís Rosa. Metodologia de avaliação da capacidade de geração de resultados de instituições financeiras. Notas Técnicas do Banco Central do Brasil, n. 26, 2002. Disponível em: <www.bcb.gov.br>. Acesso em: 20 jun. 2010.

DIANA, Marina. "Cade tem abacaxi sem facas" diz Badin sobre briga com bancos. Último Segundo. Coluna Leis e Negócios. Disponível em: <http://colunistas.ig.com.br/ leisenegocios/2010/06/29/cade-tem-abacaxi-sem-facadiz-badin-sobre-briga-com-bancos/>. Acesso em: 30 jun. 2010.

FARIA, João A.; PAULA, Luiz F.; MARINHO, Alexandre. Eficiência no setor bancário brasileiro: a experiência recente das fusões e aquisições. In: PAULA, Luiz F.; OREIRO, José L. (Org.) Sistema Financeiro: uma análise do setor bancário brasileiro. Rio de Janeiro: Elsevier, 2007, Cap. 6

FLETCHER, Mike; MANGAN, Jean; RAEBURN, Emily. Comparing hedonic models for estimating and forecasting house prices. Property Management, v. 22, n. 3, 2004. p. 189-200.

FREITAS, Paulo Springer de; KÖHLER, Marcos. Evolução e determinantes do spread. Anexo ao Relatório Preliminar da Comissão de Crise Financeira e da Empregabilidade do Senado Federal. Jun, 2009. Disponível em: <http://www.senado.gov.br. Acesso em: 26 nov. 2009.

GELOS, R. Gaston. Banking spreads in Latin America. [IMF Working Paper], WP/06/44. February, 2006. Disponível em: <http://www.imf.org. Acesso em: 30 jun. 2010.

GUJARATI, Damodar. Econometria básica. Rio de
Janeiro: Elsevier, 2006.

HAVRYLCHYK, Olena; JURZYK, Emilia. Profitability of foreign and domestic banks in Central and Eastern Europe: does the mode of entry matter? SSRN papers, January, 2006. Disponível em: <http://papers.ssrn.com/ sol3/papers.cfm?abstract_id=965735> . Acesso em: 30 jun. 2010.

MASCIANDARO, Donato; QUINTYN, Marc. Measuring financial regulation architectures and the role of the central banks: the financial supervision Herfindahl Hirschman Index. SSRN papers, 2009. Disponível em: $<$ http://ssrn.com/abstract $=1438462>$. Acesso em: 30 jun. 2010.

NAKANE, Márcio I. Concorrência e spread bancário: uma revisão da evidência no Brasil. Relatório de Economia Bancária e Crédito, Dezembro de 2003. Banco Central do Brasil. Disponível em: <http://www.bcb.gov. br/?SPREAD>. Acesso em: 29 jun. 2010.

PAGOTTO, Leopoldo U. C. Defesa da concorrência no sistema financeiro. São Paulo: Singular, 2006.

PERIA, Soledad Martínez; MODY, Ashoka. How foreign participation and market concentration impact bank spreads: evidence from Latin America. Journal of Money, Credit, and Banking, v. 36, n. 2, p. 511-537, 2002. POLDER, Michael; VELDHUIZEN, Erik; VAN DER BERGEN, Dirk; VAN DER PIJLL, Eugène. Micro and macro indicators of competition: comparison and relation with productivity change. Statistics Netherlands. The Hague/Heeren, 2009.

SECRETARIA DE ACOMPANHAMENTO ECONÔMICO (SEAE); SECRETARIA DE DIREITO ECONÔMICO (SDE). Guia de análises para atos de concentração horizontal. Portaria Conjunta SEAE/SDE no 50, de 1.8.2001. Disponível em: <http://www.seae. fazenda.gov.br $>$. Acesso em: 7 jul. 2010.

SOUZA, Gustavo José de Guimarães. A interação entre a dinâmica macroeconômica e os bancos: uma perspectiva acerca do risco de crédito. Dissertação (Mestrado) - Faculdade de Economia, Universidade Federal Fluminense, 2007.

U.S. DEPARTMENT OF JUSTICE AND THE FEDERAL TRADE COMMISSION. Horizontal merger guidelines. Disponível em: <http://www.justice.gov/atr/public/ guidelines $>$. Acesso em: 7 jul. 2010.

WORLD BANK (WB); INTERNATIONAL MONETARY FOUND (IMF). Indicators of financial structure, development, and soundness. In: Financial Sector Assessment: a Handbook. World Bank, IMF: 2005, Ch. 2. Disponível em: <http://imf.org/external/pubs/ft/ fsa/eng/ pdf/ch02.pdf $>$. Acesso em: 26 mar. 2010. 


\section{Anexos}

Tabela 8 Resultados dos testes apenas com variáveis de interesse -estatísticas $t$ entre parênteses

\begin{tabular}{|c|c|c|c|c|c|c|}
\hline \multirow{2}{*}{$\begin{array}{c}\text { Variáveis } \\
\text { independentes }\end{array}$} & \multicolumn{2}{|c|}{ Parâmetro: Ativos } & \multicolumn{2}{|c|}{ Parâmetro: Op. Créditos } & \multicolumn{2}{|c|}{ Parâmetro: Depósitos } \\
\hline & Var. Dep.: $R$ & Var. Dep.: $R$ & Var. Dep.: $R$ & Var. Dep.: $R$ & Var. Dep.: $R$ & Var. Dep.: $R$ \\
\hline \multirow{3}{*}{ Const } & 0,00297 & 0,00286 & 0,00294 & 0,00208 & 0,00577 & 0,00435 \\
\hline & $(8,037)$ & $(12,822)$ & $(11,553)$ & $(15,783)$ & $(7,747)$ & $(10,020)$ \\
\hline & $* * *$ & $* * *$ & $* * *$ & $* * *$ & $* * *$ & $* * *$ \\
\hline \multirow{3}{*}{ C4 } & $-0,00187$ & & $-0,00279$ & & $-0,00736$ & \\
\hline & $(-2,406)$ & & $(-5,146)$ & & $(-5,415)$ & \\
\hline & ** & & $* * *$ & & $* * *$ & \\
\hline \multirow{3}{*}{$\mathrm{HHI}$} & & $-0,01015$ & & $-0,00551$ & & $-0,02850$ \\
\hline & & $(-3,368)$ & & $(-3,421)$ & & $(-6,038)$ \\
\hline & & $* * *$ & & $* * *$ & & $* * *$ \\
\hline \multirow{3}{*}{$P$} & $-0,01474$ & $-0,01438$ & 0,00387 & 0,00344 & $-0,01191$ & $-0,01226$ \\
\hline & $(-3,505)$ & $(-3,414)$ & $(1,423)$ & $(1,276)$ & $(-3,037)$ & $(-3,150)$ \\
\hline & $* * *$ & $* * *$ & & & $* * *$ & $* * *$ \\
\hline Nº observações: & 18.755 & 18.755 & 17.815 & 17.815 & 17.630 & 17.630 \\
\hline$R^{2}:$ & 0,1328 & 0,1308 & 0,1201 & 0,1231 & 0,1137 & 0,1132 \\
\hline DW-stat: & 1,8074 & 1,8071 & 1,8396 & 1,8399 & 1,8340 & 1,8332 \\
\hline
\end{tabular}

Nota 1: Modelo empregado: $R_{i, t}=\beta_{0}+\beta_{1} C_{t}+\beta_{2} P_{i, t}+\varepsilon_{i, t^{\prime}}$ sendo que a variável $C$, representativa do grau de concentração do mercado, assume os indicadores $\mathrm{C} 4 \mathrm{ou} \mathrm{HHI}$.

Nota 2: Legenda para a relevância dos parâmetros: a $99 \%\left(^{* * *}\right)$; a $95 \%\left(^{* *}\right)$; e a $90 \%\left(^{*}\right)$.

Tabela 9 Resultados dos testes do modelo (5) - estatísticas $t$ entre parênteses

\begin{tabular}{|c|c|c|c|c|c|c|}
\hline \multirow{2}{*}{$\begin{array}{c}\text { Variáveis } \\
\text { independentes }\end{array}$} & \multicolumn{2}{|c|}{ Parâmetro: Ativos } & \multicolumn{2}{|c|}{ Parâmetro: Op. Créditos } & \multicolumn{2}{|c|}{ Parâmetro: Depósitos } \\
\hline & Var. Dep.: $R$ & Var. Dep.: $R$ & Var. Dep.: $R$ & Var. Dep.: $R$ & Var. Dep.: $R$ & Var. Dep.: $R$ \\
\hline \multirow{3}{*}{ Const } & 0,00014 & 0,0003 & 0,00288 & 0,00201 & 0,00471 & 0,00322 \\
\hline & $(0,072)$ & $(0,152)$ & $(1,468)$ & $(1,037)$ & $(2,240)$ & $(1,635)$ \\
\hline & & & & & $* *$ & \\
\hline \multirow{3}{*}{ C4 } & $-0,00150$ & & $-0,00281$ & & $-0,00798$ & \\
\hline & $(-1,345)$ & & $(-4,022)$ & & $(-4,813)$ & \\
\hline & & & $* * *$ & & $* * *$ & \\
\hline \multirow{3}{*}{$\mathrm{HHI}$} & & $-0,01065$ & & $-0,00634$ & & $-0,03067$ \\
\hline & & $(-2,374)$ & & $(-3,051)$ & & $(-5,212)$ \\
\hline & & $* *$ & & $* * *$ & & $* * *$ \\
\hline \multirow{3}{*}{$P$} & $-0,01499$ & $-0,01474$ & 0,00360 & 0,00325 & $-0,01166$ & $-0,01235$ \\
\hline & $(-3,288)$ & $(-3,231)$ & $(1,199)$ & $(1,083)$ & $(-2,746)$ & $(-2,917)$ \\
\hline & $* * *$ & $* * *$ & & & $* * *$ & $* * *$ \\
\hline & & & & & & \\
\hline
\end{tabular}


continuação

\begin{tabular}{|c|c|c|c|c|c|c|}
\hline \multirow{2}{*}{$\begin{array}{c}\text { Variáveis } \\
\text { independentes }\end{array}$} & \multicolumn{2}{|c|}{ Parâmetro: Ativos } & \multicolumn{2}{|c|}{ Parâmetro: Op. Créditos } & \multicolumn{2}{|c|}{ Parâmetro: Depósitos } \\
\hline & Var. Dep.: $R$ & Var. Dep.: $R$ & Var. Dep.: $R$ & Var. Dep.: $R$ & Var. Dep.: $R$ & Var. Dep.: $R$ \\
\hline \multirow{3}{*}{ J } & 0,00344 & 0,0024 & 0,00436 & 0,00512 & 0,00329 & 0,00245 \\
\hline & $(2,431)$ & $(1,578)$ & $(3,182)$ & $(3,844)$ & $(2,457)$ & $(1,762)$ \\
\hline & $* *$ & & $* * *$ & $* * *$ & ** & * \\
\hline \multirow{3}{*}{$E$} & 0.01186 & 0,0122 & 0,01302 & 0,01281 & 0,01243 & 0,01209 \\
\hline & $(4,342)$ & $(4,465)$ & $(4,783)$ & $(4,700)$ & $(4,413)$ & $(4,284)$ \\
\hline & $* * *$ & $* * *$ & $* * *$ & $* * *$ & $* * *$ & $* * *$ \\
\hline \multirow{3}{*}{$D$} & 0.00155 & 0,00148 & 0,00171 & 0,00179 & 0,00212 & 0,00226 \\
\hline & $(2,190)$ & $(2,097)$ & $(2,418)$ & $(2,527)$ & $(2,923)$ & $(3,111)$ \\
\hline & $* *$ & $* *$ & $* *$ & $* *$ & $* * *$ & $* * *$ \\
\hline \multirow[b]{2}{*}{ l } & -0.00009 & $-0,00006$ & $-0,00014$ & $-0,00016$ & $-0,00030$ & $-0,00038$ \\
\hline & $(-0,191)$ & $(-0,131)$ & $(-0,291)$ & $(-0,328)$ & $(-0,060)$ & $(-0,075)$ \\
\hline \multirow[b]{2}{*}{$\mathrm{NaC}$} & 0.00422 & 0,00422 & $-0,00059$ & $-0,00061$ & 0,00198 & 0,00199 \\
\hline & $(1,457)$ & $(1,458)$ & $(-0,190)$ & $(-0,197)$ & $(0,662)$ & $(0,665)$ \\
\hline \multirow{3}{*}{ Cont } & -0.00519 & $-0,00521$ & $-0,00043$ & $-0,00039$ & $-0,00292$ & $-0,00282$ \\
\hline & $(-4,521)$ & $(-4,531)$ & $(-0,265)$ & $(-0,242)$ & $(-2,068)$ & $(-1,999)$ \\
\hline & $* * *$ & $* * *$ & & & $* *$ & $* *$ \\
\hline No observações: & 18.755 & 18.755 & 17.815 & 17.815 & 17.630 & 17.630 \\
\hline$R^{2}:$ & 0,1189 & 0,1190 & 0,1101 & 0,1097 & 0,1049 & 0,1052 \\
\hline DW-stat: & 1,8129 & 1,8129 & 1,8461 & 1,8459 & 1,8391 & 1,8386 \\
\hline
\end{tabular}

Nota 1: Modelo empregado: $R_{i, t}=\beta_{0}+\beta_{1} C_{t}+\beta_{2} P_{i, t}+\beta_{3} J_{t}+\beta_{4} E_{t}+\beta_{5} D_{t}+\beta_{6} I_{t}+\beta_{t} N_{a c}+\beta_{i, t}$ Cont $_{i, t}+\varepsilon_{i, t}$ sendo que a variável $C$, representativa do grau de concentração do mercado, assumindo $\mathrm{C} 4$ ou $\mathrm{HHI}$.

Nota 2: Legenda para a relevância dos parâmetros: a 99\% (***); a $95 \%\left(^{* *}\right)$; e a $90 \%\left(^{*}\right)$. 